\title{
Invasive pneumococcal disease in Canada 1996: Results from Sentinel Health Unit Surveillance System
}

\author{
DA Kertesz MD FRCPC ${ }^{1}$, L Senzilet MHA MSC ${ }^{1}$, M Alagaratnam ${ }^{2}$, \\ M Lovgren MLT ART ${ }^{3}$, JA Talbot MD PhD FRCPC ${ }^{3}$, JS Spika MD ${ }^{1}$
}

$\mathrm{P}$ rotein polysacharride pneumococcal conjugate vaccines under development will provide, along with available polysacharride vaccines, an important public health intervention in the era of increasing antimicrobial resistance. Surveillance for invasive pneumococcal infections provides essential epidemiological and microbiological data to support and evaluate vaccine use.

In 1996, the Sentinel Health Unit Surveillance System (SHUSS), a network of nine Canadian health units sponsored by the Laboratory Centre for Disease Control (LCDC), Ottawa, Ontario, began laboratory-based surveillance to study invasive pneumococcal infections across the country. Sterile site pneumococcal isolates were collected by laboratories in each participating sentinel health unit, and corresponding epidemiological information was obtained for each patient. From January 1 to December 31, 1996, 430 invasive pneumococcal isolates were collected. The incidence of invasive pneumococcal disease across the SHUSS was 15.1 cases per 100,000 people per year in all ages, and 80.6 cases per 100,000 people per year in persons 85 years or older. Pneumonia was the clinical diagnosis in $65.2 \%$ of all patients, meningitis in $5.3 \%$ and bac- teremia without a clinical focus in $14.6 \%$. The overall case fatality rate for invasive pneumococcal disease was $11 \%$. Sixty per cent of those with invasive pneumococcal disease were eligible for immunization, according to the nationally established criteria. Of the 31 different capsular types identified, the five most frequent were $14,4,6 \mathrm{~B}, 9 \mathrm{~V}, 18 \mathrm{C}$ and $19 \mathrm{~F}$. Ninety-four per cent of isolates were types included in the current 23-valent pneumococcal vaccine. Among children two years of age and younger, $89 \%$ of isolates would be included in a proposed 7-valent pneumococcal conjugate vaccine currently undergoing clinical evaluation. Diminished susceptibility to penicillin (high level and intermediate) was observed in $7.4 \%$ of invasive pneumococcal isolates, and diminished susceptibility was also seen to ceftriaxone (3.8\%), erythromycin $(3.8 \%)$, ofloxacin $(4.0 \%)$ and trimethoprim/sulfamethoxazole $(16.1 \%)$. Two per cent of isolates were resistant to three or more classes of antibiotic.

The SHUSS has provided important population-based epidemiological and microbiological data about invasive pneumococcal infection that may be used to support and evaluate publicly funded immunization programs in Canada.

\footnotetext{
${ }^{1}$ Bureau of Infectious Diseases, Laboratory Centre for Disease Control; ${ }^{2}$ Environmental Health Directorate, Program Development Bureau of the Office of Environmental Health Assessment, Health Canada, Health Protection Branch, Health Canada, Ottawa, Ontario; ${ }^{3}$ National Centre for Streptococcus, Provincial Laboratory of Public Health for Northern Alberta, Edmonton, Alberta

Correspondence: Dr John S Spika, Director, Bureau of Infectious Diseases, Laboratory Centre for Disease Control, Health Canada, Ottawa, Ontario K1A OL2. Telephone 613-957-0322, fax 613-998-6413; e-mail john_spika@hc-sc.gc.ca
} 
APPENDIX 1

Participating health units in the Sentinel Health Unit Surveillance System

Okanagan Similkameen Health Board, 1340 Ellis Street, Kelowna, British Columbia V1Y 9 N1

Capital Health - Regional Public Health, 10216 - 124th Street, Suite 300, Edmonton, Alberta T5N 4A3

Saskatoon District Health - Public Health Services, 101-310 Idylwyld Drive North, Saskatoon, Saskatchewan S7L 0Z2

City of Winnipeg Community Services, 33 Warnock Street, Winnipeg, Manitoba R3E 3L6

Wellington-Dufferin, Guelph Health Unit, c/o 51 Zina Street, Orangeville, Ontario L9W 1E5

Kingston, Frontenac and Lennox \& Addington Health Unit, 221 Portsmouth Avenue, Kingston, Ontario K7M 1V5

Régie régionale de la santé et des services sociaux de l'Estrie, Direction de la santé publique, c/o 220, 12e Avenue Nord, Sherbrooke, Québec J1E 2W3

Public Health Services - Central Region Health Board, 201 Brownlow Avenue, Dartmouth, Nova Scotia B3B 1 W2

Prince Edward Island Health \& Social Services, PO Box 2000, 11 Kent Street, 2nd Floor - Jones Building, Charlottetown, Prince Edward Island C1A 7 N8 


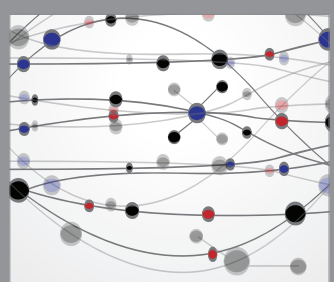

The Scientific World Journal
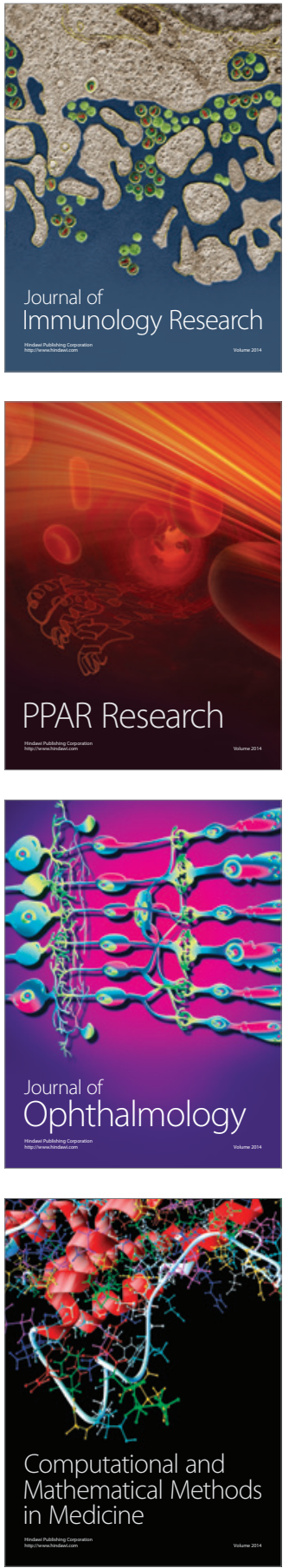

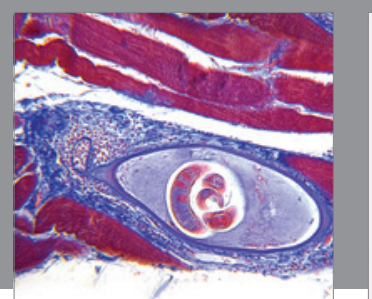

Gastroenterology Research and Practice

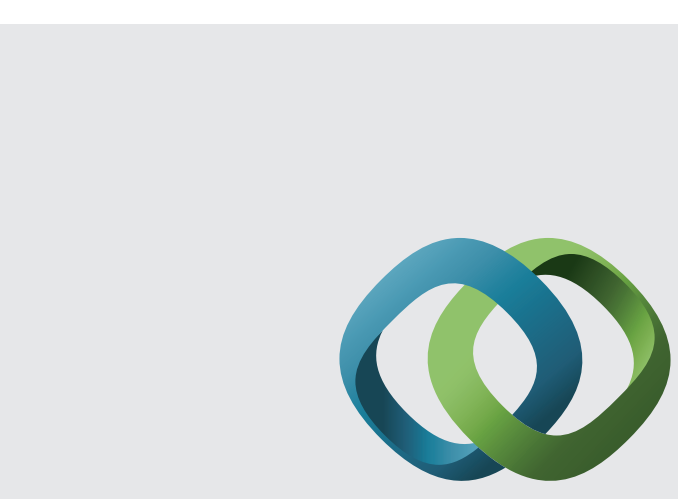

\section{Hindawi}

Submit your manuscripts at

http://www.hindawi.com
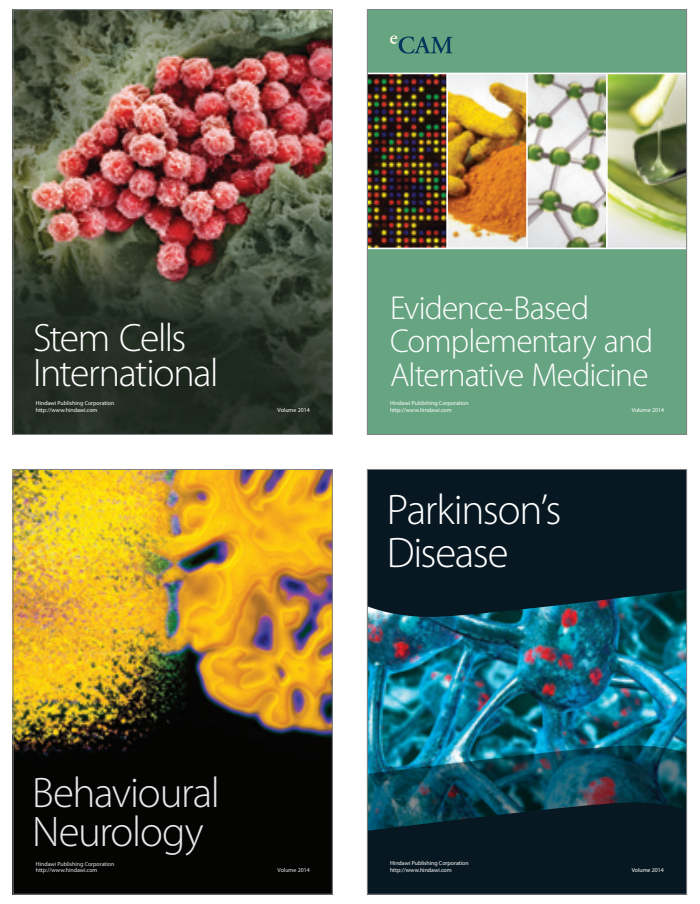
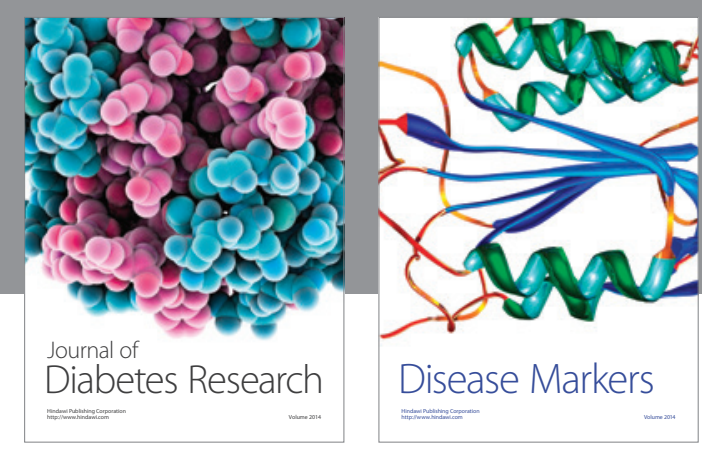

Disease Markers
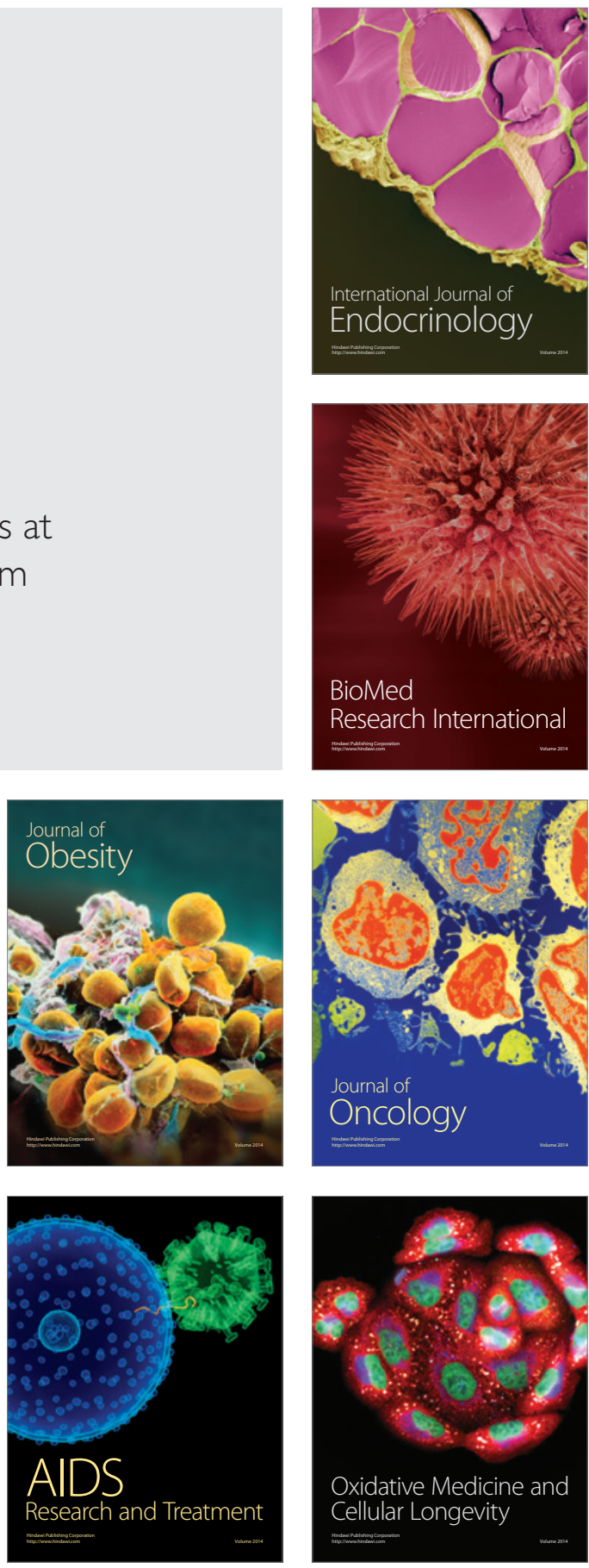